\title{
Viabilidade técnica e econômica de argamassas de revestimento produzidas com incorporação de resíduos de rochas ornamentais
}

\author{
Technical and economic viability of rendering mortar \\ produced with incorporation of ornamental rocks residue
}

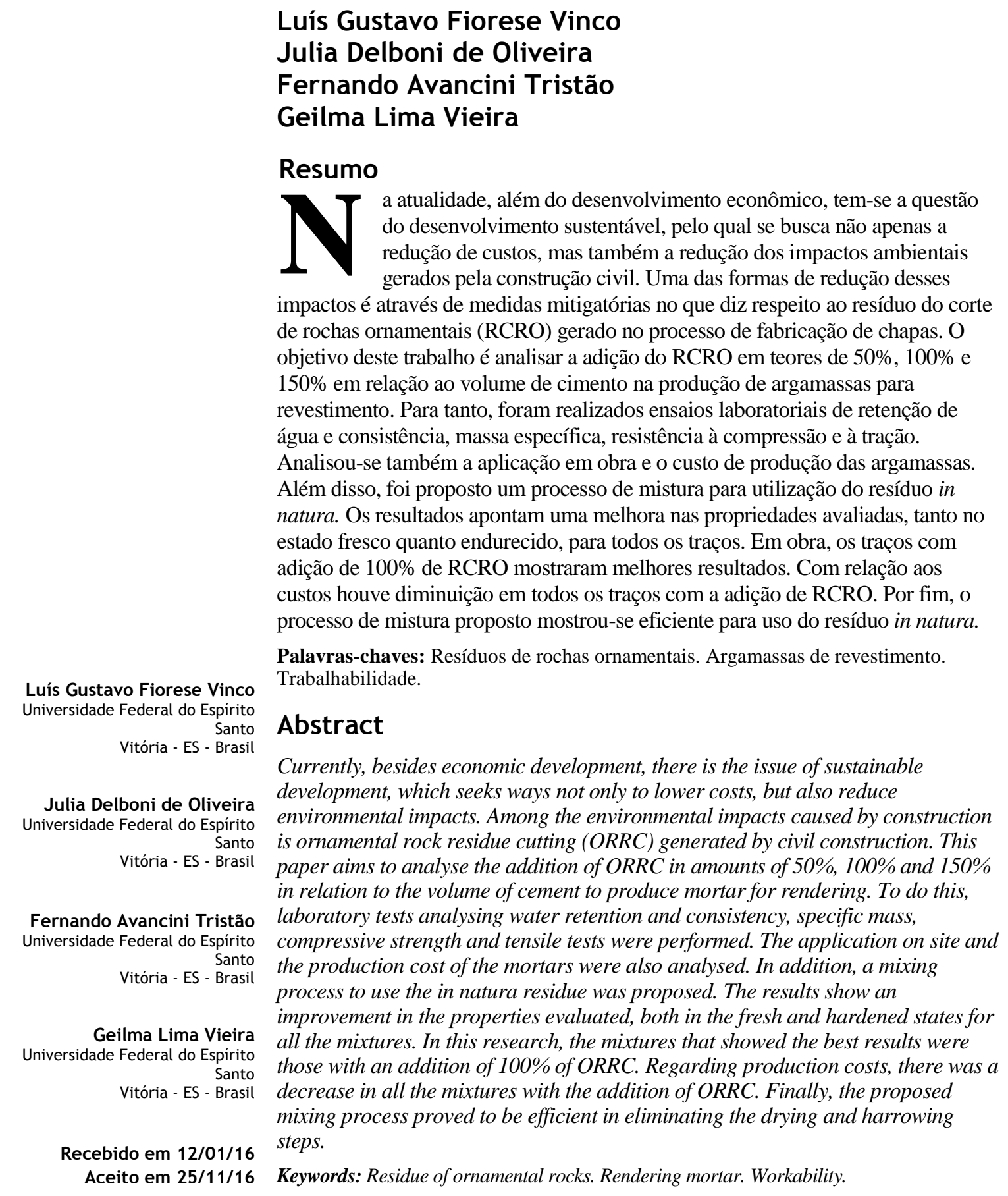

VINCO, L. G. F.; OLIVEIRA, J. D. de; TRISTÃO, F. A.; VIEIRA, G. L. Viabilidade técnica e econômica de argamassas 


\section{Introdução}

O Brasil está no grupo dos grandes produtores e exportadores do mundo do setor de rochas ornamentais. Entre os estados brasileiros destacam-se Espírito Santo, Minas Gerais, Ceará e São Paulo. O Espírito Santo exportou aproximadamente 1,5 milhão de toneladas, o que corresponde a cerca de $67 \%$ de participação no mercado nacional (ASSOCIAÇÃO..., 2013). Porém, o beneficiamento de rochas ornamentais é um processo da indústria responsável por grande geração de resíduos, tais como resíduos da extração do bloco, do desdobramento, do polimento e do corte das chapas em dimensões comerciais (GONÇALVES; MOURA; DAL MOLIN, 2002).

Diante disso, diversos estudos já foram realizados visando ao reaproveitamento do resíduo do corte de rochas ornamentais (RCRO) na construção civil. Esta é capaz de absorver os mais variados tipos de resíduos, já que é uma grande consumidora de matérias-primas e é um setor da indústria que está cada vez mais buscando formas de se obter um desenvolvimento mais sustentável (JOHN, 1996).

Um dos primeiros estudos realizados no Brasil que utilizou resíduos provenientes do processo de beneficiamento de rochas ornamentais foi desenvolvido por Calmon et al. (1997a), em que se estudaram argamassas de assentamento com traços 1:2:8 e 1:1:6 (cimento:cal:areia úmida), em volume. O resíduo do corte de granito foi utilizado em substituição à massa de cal em valores de $25 \%$, $50 \%, 75 \%$ e $100 \%$ nos traços avaliados. Segundo os autores, as argamassas no estado fresco apresentaram redução da retenção de água e maior exsudação de água. Nos ensaios realizados no estado endurecido ocorreram melhorias substanciais em todas as propriedades físicas e mecânicas analisadas. De acordo com Calmon et al. (1997a), a substituição da cal por resíduo induz a pensar que o resíduo está trabalhando como um fíler, diminuindo a porosidade das misturas, o que resulta em um incremento de resistência. Os resultados obtidos em Calmon et al. (1997b) para idades de 63 e 91 dias não apresentaram variações significativas em relação aos resultados encontrados em Calmon et al. (1997a) para a idade de 28 dias.

Cruz et al. (2003) estudaram a resistência à compressão e o módulo de elasticidade das argamassas com diferentes porcentagens do resíduo do corte de rochas em substituição à areia. O traço utilizado como referência foi $1: 3$ (cimento:areia), em massa. As porcentagens de substituição de areia por resíduo foram de $5 \%$,
$10 \%, 15 \%$ e $20 \%$ (em volume), baseando-se nos estudos de Moura et al. (2006). Quanto à resistência à compressão axial das argamassas, em geral se elevou da idade de 7 dias até a idade de 28 dias, com a inserção do resíduo. Os melhores resultados de resistência à compressão axial foram obtidos em duas amostras com percentuais de substituição de resíduo de $15 \%$ e de $20 \%$. Os módulos de elasticidade se elevaram até o percentual de substituição do resíduo de $15 \%$, e para $20 \%$ houve diminuição desses valores.

Corinaldesi, Moriconi e Naik (2010) utilizaram resíduo de mármore como substituição ao cimento e à areia em argamassas com teor de $10 \%$ em relação à massa de cimento. Os autores também realizaram uma caracterização física e química do material em que constataram a elevada finura dele, que são as principais características quando se utiliza o resíduo como fíler. Com relação à resistência à compressão das argamassas, os ensaios mostraram queda de $10 \%$ nos valores quando o resíduo foi utilizado em substituição ao agregado miúdo e queda de $20 \%$ quando usado em substituição ao cimento.

Al-Akhras, Ababneh e Alaraji (2010) avaliaram o comportamento de argamassas com utilização de resíduo do corte de rochas ornamentais após queima a $700{ }^{\circ} \mathrm{C}$. O resíduo foi usado com substituição parcial do cimento e da areia em teores de $0 \%, 5 \%, 10 \%$ e $15 \%$, e as propriedades avaliadas foram trabalhabilidade, resistência à compressão e à flexão, e microestrutura das misturas. Os resultados mostram potencial no uso do resíduo em argamassas, uma vez que os valores de resistência à compressão e flexão mostraram crescimento com o aumento no teor de resíduo até $15 \%$, e para o teor de $10 \%$ de resíduo as argamassas apresentaram menor porosidade quando comparadas com argamassa de controle. Com relação à trabalhabilidade, as argamassas com resíduo apresentaram decréscimo nessa propriedade, justificado possivelmente devido à elevada área superficial específica do resíduo.

Colangelo, Marroccoli e Cioffi (2010) também avaliaram argamassas com substituição parcial do cimento e areia por resíduo de mármore, porém em teores de $10 \%, 20 \%$ e $30 \%$ em relação ao agregado e em $10 \%, 15 \%$ e $20 \%$ em relação ao cimento. Também foi utilizado aditivo superplastificante em todas as misturas a fim de avaliar a trabalhabilidade. Os autores avaliaram a resistência à compressão das misturas e concluíram que para utilização do resíduo em substituição ao agregado há melhora nessa propriedade em todos os teores de resíduo utilizados. Já para substituição do 
cimento os teores acima de $10 \%$ mostraram decréscimo nos valores de resistência à compressão. Com relação à trabalhabilidade observou-se que houve melhora nessa propriedade com a adição do resíduo, principalmente com a diminuição na quantidade requerida de aditivo.

Vardhan et al. (2015) estudaram o efeito da substituição parcial do cimento por resíduo de mármore em argamassas cimentíceas em teores de $10 \%, 20 \%, 30 \%, 40 \%$ e $50 \%$. Foram avaliadas as propriedades de trabalhabilidade, resistência à compressão e microestrutura das misturas. Os autores concluíram que é possível utilizar o resíduo de mármore em substituição ao cimento em até $10 \%$ sem diminuição da resistência à compressão, e ainda com melhora da trabalhabilidade da mistura. Para teores maiores que $10 \%$ há decréscimo na resistência à compressão das misturas, possivelmente explicada pela elevação na porosidade das argamassas com substituição do cimento por resíduo de mármore, observada na avalição da microestrutura.

Segundo Uliana (2014), o RCRO vem sendo utilizado em diversos produtos da construção civil, como blocos, telhas, ladrilhos, argamassas e concretos, principalmente levando em consideração o efeito fíler que a aplicação do resíduo proporciona. A incorporação do RCRO busca melhorias no comportamento mecânico dos materiais e na durabilidade, além de proporcionar redução no uso de agregados naturais e aglomerantes. A autora estudou a aplicação de tratamento térmico ao RCRO (com e sem granalha) objetivando a produção de material pozolânico. O material foi caracterizado e utilizado como substituição ao material cimentício em teores de $5 \%, 10 \%, 15 \%$ e $20 \%$ em volume, de forma a avaliar seu comportamento mecânico e a atividade pozolânica. Como resultado concluiu-se que em relação ao comportamento mecânico (resistência à compressão axial) todas as argamassas com substituição de cimento por RCRO após tratamento térmico apresentaram comportamento semelhante ao da argamassa referência (sem substituição), principalmente quando ensaiados aos 91 dias de idade. Esse comportamento pode ser explicado devido à pozolanicidade do material, comprovada pelo ensaio de índice de atividade pozolânica com o cimento (ULIANA, 2014).

O objetivo deste trabalho foi avaliar as propriedades no estado fresco e endurecido de argamassas de revestimento produzidas com incorporação do RCRO in natura, ou seja, sem nenhum tipo de beneficiamento. Foram utilizados teores de $50 \%, 100 \%$ e $150 \%$ de RCRO em relação ao volume de cimento para avaliar o efeito da adição de resíduo, atuando como um fíler, nas propriedades de retenção de água e consistência, massa específica, resistência à compressão e à tração. De forma a viabilizar a utilização do resíduo in natura nas argamassas, foi desenvolvido um processo de mistura que visa à eliminação de possíveis torrões de resíduo.

Além disso, foi realizada uma análise da aplicação em obra das argamassas com incorporação de RCRO, em que se analisaram características relacionadas à trabalhabilidade delas, com auxílio de oficiais pedreiros. Por fim, foi elaborada uma análise do custo de produção, de forma a avaliar o benefício econômico dessa incorporação, aliado ao benefício ambiental trazido pela utilização do RCRO pela construção civil.

\section{Materiais e métodos}

\section{Caracterização dos materiais}

\section{Resíduo do Corte de Rochas Ornamentais (RCRO)}

O resíduo utilizado é proveniente de uma empresa que beneficia rochas ornamentais e utiliza teares convencionais com uso de lâminas metálicas e granalhas para o corte dos blocos, como exemplificado na Figura 1. Isso gera uma lama abrasiva que inicialmente é tratada com o uso de filtro-prensa para diminuição da umidade.

Figura 1 - Processo de geração do RCRO com tear convencional
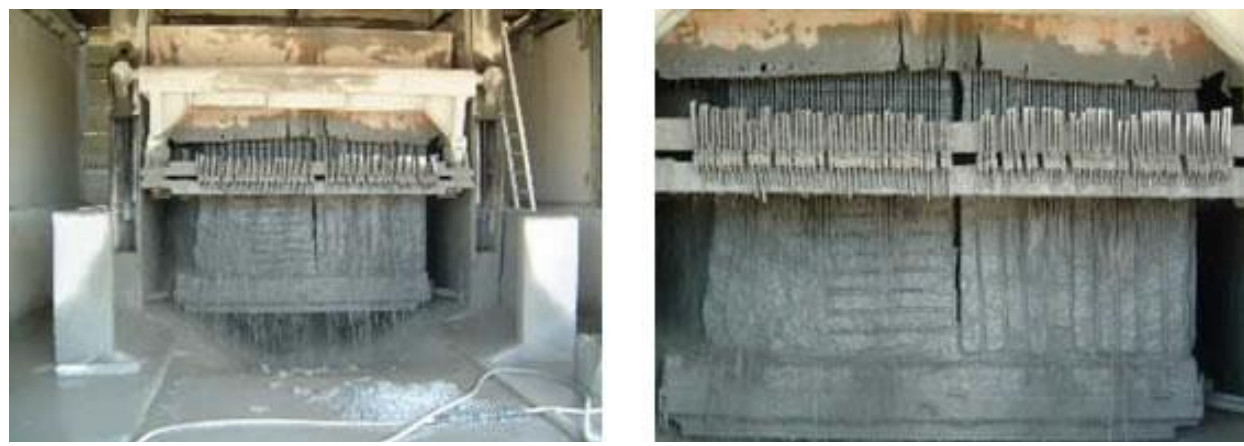

Fonte: Barros et al. (2006). 
A caracterização física do RCRO encontra-se na Tabela 1.

A caracterização química do RCRO encontra-se na Tabela 2. É possível observar que o RCRO é composto predominantemente de $\mathrm{SiO}_{2}$ e $\mathrm{Al}_{2} \mathrm{O}_{3}$, o que indica a origem a partir de rocha graníticas (ARAÚJO; GOMES; FERREIRA, 2002). A presença dos óxidos $\mathrm{Fe}_{2} \mathrm{O}_{3}$ e $\mathrm{CaO}$ devem-se principalmente ao desgaste da granalha e das lâminas dos teares e ao uso da cal respectivamente.

Na Figura 2 é apresentado o difratograma de raios $\mathrm{X}$ do RCRO. É possível identificar picos bem definidos, que são característicos de compostos quimicamente estáveis e com baixa possibilidade de atividade reativa (ULIANA, 2014).

\section{Tabela 1 - Caracterização física do resíduo do corte de rochas ornamentais}

\begin{tabular}{c|c|c}
\hline Ensaios & Resultados & Normas (ABNT) \\
\hline Massa específica $\left(\mathrm{kg} / \mathrm{dm}^{3}\right)$ & 2,546 & NBR NM 52 (ABNT, 2009) \\
Massa unitária $\left(\mathrm{kg} / \mathrm{dm}^{3}\right)-$ Adotada & 1,5 & NBR NM 45 (ABNT, 2006) \\
Finura - retido na peneira 200 $(\%)$ & 7,38 & NBR 11579 (ABNT, 2012) \\
Área específica $\left(\mathrm{cm}^{2} / \mathrm{g}\right)$ & 5133,5 & NBR NM 76 (ABNT, 1998) \\
\hline
\end{tabular}

Tabela 2 - Caracterização química do resíduo do corte de rochas ornamentais

\begin{tabular}{c|c}
\hline Óxidos & \% \\
\hline $\mathrm{SiO}_{2}$ & 57,89 \\
$\mathrm{Al}_{2} \mathrm{O}_{3}$ & 24,86 \\
$\mathrm{Fe}_{2} \mathrm{O}_{3}$ & 4,14 \\
$\mathrm{Na}_{2} \mathrm{O}$ & 3,22 \\
$\mathrm{MgO}$ & 3,15 \\
$\mathrm{~K}_{2} \mathrm{O}$ & 2,91 \\
$\mathrm{CaO}$ & 2,74 \\
$\mathrm{TiO}_{2}$ & 0,46 \\
$\mathrm{P}_{2} \mathrm{O}_{5}$ & 0,21 \\
$\mathrm{SO}_{3}$ & 0,15 \\
$\mathrm{BaO}$ & 0,15 \\
$\mathrm{MnO}$ & 0,06 \\
$\mathrm{ZrO}$ & 0,03 \\
$\mathrm{SrO}$ & 0,02 \\
$\mathrm{ZnO}$ & 0,01 \\
\hline
\end{tabular}

Fonte: Relatório de Análise de Materiais do CTGAS-ER (CENTRO..., 2016).

Figura 2 - Difratograma de raios X do RCRO

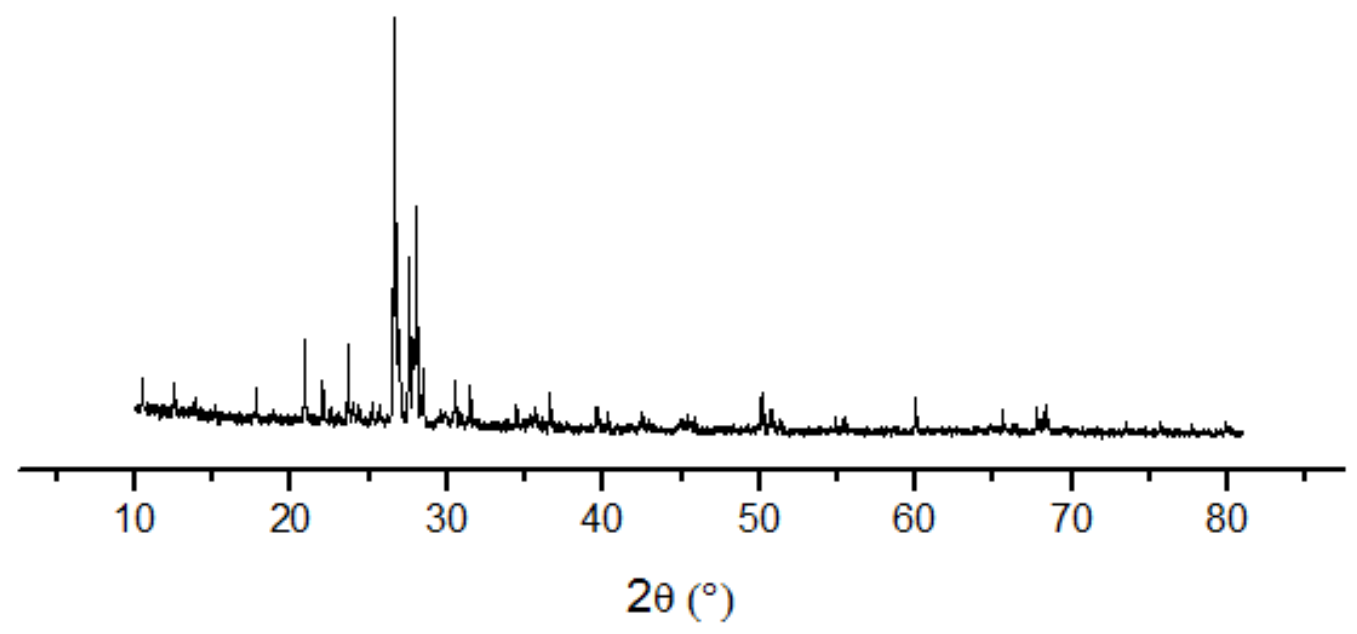

168 Vinco, L. G. F.; Oliveira, J. D. de; Tristão, F. A.; Vieira, G. L. 


\section{Cimento}

Utilizou-se o cimento CPII - F - 32 para realização das misturas, uma vez que é o mesmo utilizado pela construtora nas análises das argamassas em obra, com o objetivo de uma efetiva comparação dos resultados. Além disso, é um cimento comumente utilizado na produção de argamassas de revestimento. A caracterização do cimento é apresentada na Tabela 3.

\section{Cal}

Utilizou-se nas argamassas a cal CH III, pois é a mesma utilizada pela construtora onde se realizou a análise das argamassas em obras e por ser um material comumente encontrado no mercado local. A cal apresenta massa unitária de $0,96 \mathrm{~kg} / \mathrm{dm}^{3}$ (ABNT, 2006) e finura de 7,35\% retidos na peneira 200 (NBR 11579 (ABNT, 2012)).

\section{Agregado}

O agregado miúdo utilizado para produção das argamassas foi areia lavada de rio, e sua caracterização encontra-se na Tabela 4.

\section{Aditivo incorporador de ar (AD)}

$\mathrm{Na}$ produção das argamassas foi utilizado aditivo incorporador de ar com o intuito de avaliar a trabalhabilidade em obra e também como uma alternativa à utilização da cal. A caracterização, de acordo com fabricante, encontra-se na Tabela 5.

\section{Dosagem das argamassas}

A Tabela 6 apresenta os nove traços estudados. O traço referência (TR) foi obtido com uma empresa de construção civil que utiliza RCRO como agregado na composição das argamassas de revestimento. Nos traços 2 e 3 adicionaram-se $100 \%$ e $150 \%$ de RCRO em relação ao volume de cimento ao traço referência respectivamente.

Tabela 3 - Caracterização do cimento

\begin{tabular}{|c|c|c|c|}
\hline \multicolumn{2}{|l|}{ Ensaios } & Resultados & Normas (ABNT) \\
\hline \multicolumn{2}{|l|}{ Finura $(\%)$} & 3,66 & NBR $11579($ ABNT, 2012) \\
\hline \multicolumn{2}{|l|}{ Massa específica $\left(\mathrm{kg} / \mathrm{dm}^{3}\right)$} & 2,726 & NBR NM 23 (ABNT, 2001) \\
\hline \multirow{2}{*}{ Tempo de pega (h:min) } & Início & $02: 35$ & \multirow{2}{*}{ NBR NM 65 (ABNT, 2003a) } \\
\hline & Término & $04: 10$ & \\
\hline \multicolumn{2}{|l|}{ Área específica $\left(\mathrm{cm}^{2} / \mathrm{g}\right)$} & 3443,4 & NBR NM 76* (ABNT, 1998) \\
\hline \multicolumn{2}{|c|}{ Massa unitária $\left(\mathrm{kg} / \mathrm{dm}^{3}\right)$} & 0,865 & NBR 12127 (ABNT, 1991) \\
\hline \multicolumn{2}{|c|}{ Água da pasta de consistência normal (\%) } & 26,4 & NBR NM 43 (ABNT, 2003b) \\
\hline \multirow{3}{*}{ Resistência à compressão axial (MPa) } & 3 Dias & 14,96 & \multirow{3}{*}{ NBR 7215 (ABNT, 1996a) } \\
\hline & 7 Dias & 20,8 & \\
\hline & 28 Dias & 34,95 & \\
\hline
\end{tabular}

Nota: *a NBR NM 76 (ABNT, 1998) foi substituída pela NBR 16372 (ABNT, 2015) depois da realização do ensaio.

Tabela 4 - Caracterização do agregado miúdo

\begin{tabular}{c|c|c}
\hline Ensaios & Resultados & Normas (ABNT) \\
\hline Módulo de finura & 2,14 & NBR NM 248 (ABNT, 2003b) \\
Dimensão máxima característica $(\mathrm{mm})$ & 1,2 & NBR NM 248 (ABNT, 2003b) \\
Massa específica $\left(\mathrm{kg} / \mathrm{dm}^{3}\right)$ & 2,628 & NBR NM 52 (ABNT, 2009) \\
Massa unitária $\left(\mathrm{kg} / \mathrm{dm}^{3}\right)$ & 1,29 & NBR NM 45 (ABNT, 2006) \\
\hline
\end{tabular}

Tabela 5 - Caracterização do aditivo

\begin{tabular}{c|c}
\hline Características & Resultados \\
\hline Aspecto & Líquido \\
Cor & Castanho \\
Densidade a $25 \%(\mathrm{~g} / \mathrm{ml})$ & 1 \\
$\mathrm{pH}$ & $9,5 \mathrm{a} 11$ \\
Consumo para cada $50 \mathrm{~kg}$ de cimento $(\mathrm{ml})$ & 100 \\
\hline
\end{tabular}

Fonte: Ficha Técnica da Viapol (2014). 
Tabela 6 - Dosagem das argamassas de revestimento com RCRO

\begin{tabular}{|c|c|c|c|c|}
\hline \multirow{2}{*}{$\begin{array}{c}\mathbf{N}^{\circ} \\
\text { Traço }\end{array}$} & \multicolumn{2}{|c|}{$\begin{array}{c}\text { Traço } \\
\text { (cimento : cal : resíduo : areia) }\end{array}$} & \multirow{2}{*}{$\begin{array}{l}\text { Aditivo/cimento } \\
\text { (massa) }\end{array}$} & \multirow{2}{*}{$\begin{array}{c}\mathrm{A} / \mathrm{C} \\
(\mathbf{m a s s a})\end{array}$} \\
\hline & Volume & Massa & & \\
\hline TR & $1: 0: 0.5: 5$ & $1: 0: 0.68: 5.86$ & - & 1,34 \\
\hline 2 & $1: 0: 1: 5$ & $1: 0: 1.36: 5.86$ & - & 1,38 \\
\hline 3 & $1: 0: 1.5: 5$ & $1: 0: 2.04: 5.86$ & - & 1,42 \\
\hline 4 & $1: 0: 0.5: 5+\mathrm{AD}$ & $1: 0: 0.68: 5.86$ & 0,002 & 1,18 \\
\hline 5 & $1: 0: 1: 5+\mathrm{AD}$ & $1: 0: 1.36: 5.86$ & 0,002 & 1,21 \\
\hline 6 & $1: 0: 1.5: 5+\mathrm{AD}$ & $1: 0: 2.04: 5.86$ & 0,002 & 1,31 \\
\hline 7 & $1: 0.5: 0.5: 5$ & $1: 0.32: 0.68: 5.86$ & - & 1,36 \\
\hline 8 & $1: 0.5: 1: 5$ & $1: 0.32: 1.36: 5: 86$ & - & 1,37 \\
\hline 9 & $1: 0.5: 1.5: 5$ & $1: 0.32: 2.04: 5.86$ & - & 1,40 \\
\hline
\end{tabular}

Nos traços 4, 5 e 6 foi adicionado aditivo incorporador de ar (AD) de acordo com a indicação do fabricante, mantendo-se as relações de adição de RCRO dos traços TR, 2 e 3 respectivamente. Por fim, nos traços 7,8 e 9 substituiu-se o $\mathrm{AD}$ por $50 \%$ de adição de cal em relação ao volume de cimento.

Neste trabalho optou-se por avaliar porcentagens elevadas de adição de resíduo às misturas de forma proporcional à referência (50\%), chegando-se aos valores de $100 \%$ e $150 \%$. Os teores utilizados têm como objetivo determinar se é possível adicionar resíduo em grandes quantidades às argamassas sem prejuízo técnico e de aplicabilidade delas. Observou-se a partir da literatura que normalmente são realizadas substituições de frações de cimento e/ou areia e que geralmente não é avaliado o resíduo como adição em relação a esses materiais.

\section{Procedimento de mistura}

A partir de estudos feitos por diversos autores, como Calmon et al. (1997a), Gonçalves, Moura e Dal Molin (2002), Tenório, Lameiras e Lima (2005), Moura et al. (2006), Soares (2014) e Uliana (2014), notou-se que para a utilização do resíduo do beneficiamento de rochas ornamentais em argamassas ele foi seco ao ar ou em estufa e em seguida destorroado antes de ser adicionado à mistura. Portanto, visando à diminuição de custos e à otimização de etapas para a utilização do RCRO, foi proposto um procedimento de mistura em que se utiliza o resíduo in natura (Figura 3), para a homogeneização da argamassa.

Como o RCRO encontra-se com certa umidade devido às condições de deposição e transporte, neste trabalho optou-se por adicionar água à mistura, de forma que as argamassas apresentassem índice de consistência de $265 \pm 20$ $\mathrm{mm}$.

O procedimento para mistura e homogeneização criado e utilizado é descrito a seguir: (a) umedecer a betoneira/argamassadeira;

(b) Adicionar o RCRO e parte da água de amassamento $(\approx 70 \%)$ e acionar o equipamento de mistura por $2 \mathrm{~min}$;

(c) adicionar areia e o restante da água no equipamento de mistura e misturar por mais $1 \mathrm{~min}$.

(d) adicionar o cimento e/ou a cal e misturar por mais $3 \mathrm{~min}$;

(e) adicionar o aditivo se utilizado; e

(f) corrigir, se necessário, a água para se atingirem a consistência e a trabalhabilidade adequadas.

\section{Análise das argamassas}

\section{Em laboratório}

Foram realizados ensaios para avaliar se as propriedades no estado fresco e no estado endurecido das argamassas propostas na Tabela 6 atendem aos parâmetros descritos pelas normas técnicas da ABNT. Os ensaios realizados no estado fresco e endurecido encontram-se nos Quadros 1 e 2 respectivamente.

Para o ensaio de retenção de água, o tempo de sucção foi de 1 min no funil de Buchner, de acordo com a NBR 9290 (ABNT, 1996b) - Cal hidratada para argamassa - Determinação de retenção de água. $\mathrm{O}$ índice de consistência foi fixado em $265 \pm 20 \mathrm{~mm}$, de forma a atender às condições de obra, que são menos controláveis que as de laboratório.

Após a realização dos ensaios no estado fresco as mesmas argamassas foram utilizadas para moldar corpos de prova para avaliação das propriedades no estado endurecido. Para os ensaios de tração na flexão e compressão axial foram moldados corpos de prova de $4 \times 4 \times 16 \mathrm{~cm}$, mantidos por $24 \mathrm{~h} \mathrm{em}$ câmara úmida e em seguida mantidos em uma sala com temperatura de $22 \pm 2{ }^{\circ} \mathrm{C}$ e umidade relativa de 
$80 \pm 5 \%$ até os dias dos ensaios, que ocorreram com 14 e 28 dias.

Para uma melhor avaliação do comportamento das argamassas com adição de RCRO foi realizada uma análise estatística nos resultados dos ensaios no estado fresco e endurecido realizados em laboratório para todos os traços propostos. O software utilizado para a análise foi o Statistica ${ }^{\circledR}$, versão 7.0 .

Para a validação dos resultados utilizou-se a metodologia estatística de análise de variância (ANOVA), que avalia a significância de diversos fatores e suas interações. O nível de significância adotado para a análise foi de $5 \%$, ou seja, o intervalo de confiança na decisão é de $95 \%$. Como resultado da análise, o software Statistica ${ }^{\circledR}$ gera um parâmetro $p$, que, se for menor que 0,05 , influencia significativamente no resultado analisado; caso contrário, o fator não exerce influência significativa.

Para possibilitar a análise estatística dos resultados quantitativos em laboratório, foi elaborada uma matriz experimental contemplando todas as variáveis envolvidas no processo, que foram classificadas como variáveis de resposta (ou variáveis dependentes), variáveis independentes (ou fatores controláveis) e variáveis de controle:

(a) variáveis de resposta no estado fresco: retenção de água, retenção de consistência e massa específica;

(b) variáveis de resposta no estado endurecido: resistência à compressão e resistência à tração;

(c) variáveis independentes: porcentagem de adição do resíduo em três níveis $(50 \%, 100 \%$ e $150 \%$ de adição em relação ao volume de cimento); porcentagem de cal em dois níveis $(0 \%$ e $50 \%$ de adição em relação ao volume de cimento); presença do aditivo em dois níveis (com e sem aditivo); e

(d) variáveis de controle (mantidas constantes): relação areia/cimento $(5,86 / 1)$, em massa; relação cal/cimento $(0,32 / 1)$, em massa; relação aditivo/cimento (0,002/1), em massa.

\section{Figura 3 - Resíduo do corte de rochas ornamentais in natura}

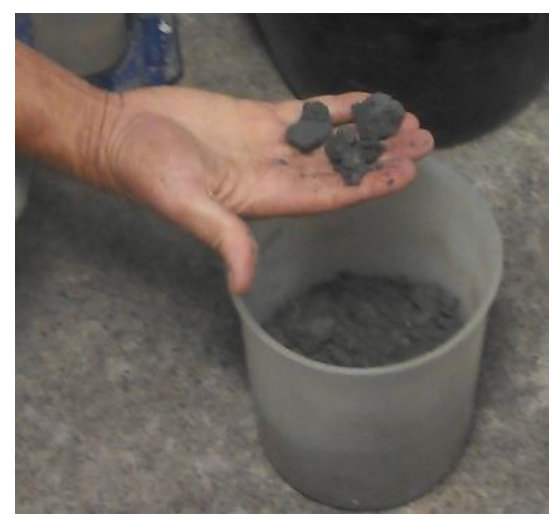

Quadro 1 - Ensaios realizados na argamassa no estado fresco

\begin{tabular}{|c|c|}
\hline Ensaios & Normas (ABNT) \\
\hline Índice de consistência & NBR 13276 (ABNT, 2005a) \\
Massa específica e teor de ar & NBR 13278 (ABNT, 2005b) \\
Retenção de água & NBR 9290 (ABNT, 1996b) \\
Retenção de consistência & NBR 13277 (ABNT, 2005c) \\
\hline
\end{tabular}

Quadro 2 - Ensaios realizados na argamassa no estado endurecido

\begin{tabular}{|c|c|}
\hline Ensaios & \multicolumn{1}{|c|}{ Normas (ABNT) } \\
\hline Resistência à compressão & NBR 13279 (ABNT, 2005d) \\
Resistência à tração na flexão & NBR 13279 (ABNT, 2005d) \\
\hline
\end{tabular}




\section{Em obra}

$\mathrm{Na}$ análise em obra foram empregados todos os traços descritos anteriormente na Tabela 6 , e as argamassas foram produzidas com os mesmos componentes descritos no item 2.1. Para a execução do revestimento de argamassa e análise dos traços propostos foram selecionados três pedreiros, e cada um executou e avaliou os nove traços em questão neste trabalho, em momentos distintos.

A espessura do revestimento foi fixada em $2 \pm 1 \mathrm{~cm}$ para todos os tipos de argamassa. Após a conferência do taliscamento as argamassas foram lançadas manualmente em faixas de amostragem com dimensões definidas por seu rendimento, o que variou de acordo com cada traço. As argamassas foram lançadas sobre blocos cerâmicos com chapisco com traço 1:3 (cimento:areia) em volume, sem nenhum tipo de umedecimento da superfície antes do lançamento.

A análise das argamassas foi feita no estado fresco pelos três pedreiros que as empregaram, e as principais propriedades avaliadas foram plasticidade, adesão inicial, homogeneidade e trabalhabilidade.

\section{Resultados e discussão}

\section{Procedimento de mistura}

Com relação ao método de preparo da argamassa, foi no estado fresco que se evidenciou o processo de homogeneização proposto na metodologia, que visava à eliminação das etapas de secagem e destorroamento. A intenção desse modo de preparo é evitar a formação de aglomerados de resíduo, que prejudicam a homogeneidade da argamassa. $\mathrm{O}$ processo se mostrou eficiente em uma análise visual da argamassa, atendendo-se em princípio à hipótese levantada de que é possível utilizar o RCRO conforme se apresenta, in natura, sem a necessidade de secagem e destorroamento.

Porém, no estado endurecido todas as argamassas evidenciaram pequenos pontos isolados em que o resíduo se aglomerou e não se homogeneizou completamente com os demais materiais.

A presença desses pequenos aglomerados pode ser prejudicial, pois o resíduo do corte de rochas ornamentais, quando na forma de pequenos grumos, se destorroa facilmente, podendo gerar pequenos vazios no revestimento de argamassa. Em casos em que forem utilizados acabamentos como revestimento cerâmico e massa corrida esses vazios poderão ser desconsiderados, pois a utilização deles anula os possíveis efeitos degradantes da formação de aglomerados, tornando o processo de mistura aplicável.

\section{Propriedades das argamassas no estado fresco}

Com base na metodologia adotada e nas normas técnicas da ABNT, obtiveram-se os resultados dos ensaios realizados nas argamassas no estado fresco, que estão apresentados na Tabela 7; e na Tabela 8 são apresentados os resultados da ANOVA para as propriedades avaliadas. Vale ressaltar que o parâmetro teor de ar incorporado é calculado com base nos resultados da massa específica, e, portanto, a análise realizada para a massa específica vale também para o teor de ar incorporado.

A Figura 4 apresenta o resultado da análise estatística para o comportamento das misturas no estado fresco em função da utilização do RCRO para análise da retenção de água e consistência.

Tabela 7 - Resultados obtidos nas argamassas no estado fresco

\begin{tabular}{c|c|c|c|c|c|c}
\hline $\begin{array}{c}\mathbf{N}^{\mathbf{o}} \\
\text { traço }\end{array}$ & $\begin{array}{c}\text { Traço em volume } \\
\text { (cimento }: \text { cal : } \\
\text { resíduo }: \text { areia) }\end{array}$ & $\begin{array}{c}\text { Índice de } \\
\text { consistência } \\
(\mathbf{m m})\end{array}$ & $\begin{array}{c}\text { Retenção } \\
\text { de água } \\
(\%)\end{array}$ & $\begin{array}{c}\text { Retenção de } \\
\text { consistência } \\
(\%)\end{array}$ & $\begin{array}{c}\text { Massa } \\
\text { específica } \\
\left(\mathbf{k g} / \mathbf{d m}^{\mathbf{3}}\right)\end{array}$ & $\begin{array}{c}\text { Ar } \\
\text { incorporado } \\
(\%)\end{array}$ \\
\hline $\mathrm{TR}$ & $1: 0: 0.5: 5$ & 264 & 86 & 55 & 1,99 & 5,7 \\
2 & $1: 0: 1: 5$ & 257 & 89 & 62 & 2,00 & 7,0 \\
3 & $1: 0: 1.5: 5$ & 266 & 92 & 70 & 2,02 & 4,3 \\
4 & $1: 0: 0.5: 5+\mathrm{AD}$ & 265 & 90 & 68 & 1,78 & 18,0 \\
5 & $1: 0: 1: 5+\mathrm{AD}$ & 262 & 92 & 72 & 1,80 & 17,1 \\
6 & $1: 0: 1.5: 5+\mathrm{AD}$ & 270 & 95 & 76 & 1,82 & 14,6 \\
7 & $1: 0.5: 0.5: 5$ & 280 & 93 & 75 & 1,90 & 11,6 \\
8 & $1: 0.5: 1: 5$ & 260 & 95 & 76 & 1,97 & 9,2 \\
9 & $1: 0.5: 1.5: 5$ & 264 & 97 & 79 & 2,00 & 7,0 \\
\hline
\end{tabular}

172 Vinco, L. G. F.; Oliveira, J. D. de; Tristão, F. A.; Vieira, G. L. 
Tabela 8 - Resultados da ANOVA em relação às propriedades no estado fresco

\begin{tabular}{c|c|c|c}
\hline Variável independente & Variável resposta & $\boldsymbol{P}$ & Significância \\
\hline Resíduo & Retenção de água e de consistência & 0,266432 & Não significativo \\
Cal & Retenção de água e de consistência & 0,211382 & Não significativo \\
Aditivo & Retenção de água e de consistência & 0,455672 & Não significativo \\
Resíduo & Massa específica & 0,816779 & Não significativo \\
Cal & Massa específica & 0,457644 & Não significativo \\
Aditivo & Massa específica & 0,000252 & Significativo \\
\hline
\end{tabular}

Figura 4 - Resultado da análise estatística para o ensaio de retenção de água e consistência para a variável resíduo

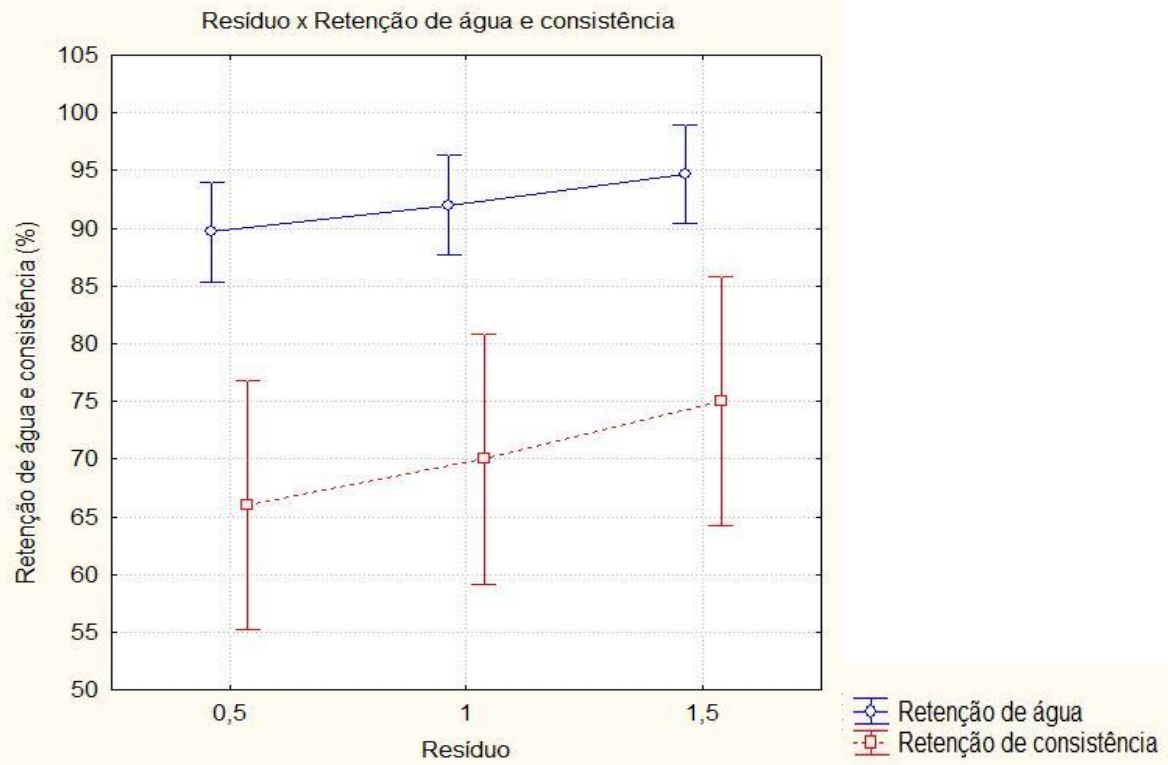

Para a retenção de água e consistência foi constatada, através da ANOVA, a não significância dos fatores resíduo, cal e aditivo. Apesar da não significância das variáveis estudadas, é importante observar a tendência de comportamento dos fatores controláveis e das variáveis de respostas. Analisando os resultados, observou-se no Figura 4 que, com o aumento da porcentagem de adição do RCRO, houve tendência de crescimento nas propriedades avaliadas para todos os traços analisados. Devido à elevada finura do resíduo, evidenciada por sua área específica de $5.133,5 \mathrm{~cm}^{2} / \mathrm{g}$, que é da mesma ordem de grandeza que a do cimento, aquele possivelmente contribuiu para a colmatação dos vazios da argamassa, diminuindo a velocidade de percolação da água por seus poros, fazendo com que a argamassa retivesse a água por mais tempo, o que aconteceu também nos estudos de Gonçalves, Moura e Dal Molin (2002) e Calmon et al. (1997a).

A Figura 5 apresenta os resultados da análise estatística para o comportamento das misturas no estado fresco em função da utilização do RCRO e do aditivo para análise da massa específica.

Já para a massa específica, foi constatada através da ANOVA a significância apenas do fator aditivo, e a não significância dos fatores resíduo e cal. Contudo, observa-se na Figura 5a tendência de crescimento na propriedade avaliada, que pode estar relacionada com a maior quantidade em massa de resíduo que foi incorporada em cada nível do fator e também ao fato de que a massa específica do RCRO é maior em relação aos demais materiais constituintes da argamassa, como observado por Tenório, Lameiras e Lima (2005) e Uliana (2014). Carasek (2007) também observou esse fato quando afirma que a massa específica das argamassas varia de acordo com a massa específica de seus materiais constituintes.

Por fim, observa-se na Figura $5 \mathrm{~b}$ que, com a adição de aditivo, ocorre decréscimo na massa específica, que se deve, possivelmente, ao aumento de microbolhas de ar na matriz da argamassa devido às características do aditivo, o que contribui 
para a diminuição da massa específica, como também observado por Calhau (2000).

Na Tabela 9 são apresentados os resultados de resistência à compressão e à tração e na Tabela 10 os resultados da ANOVA para as propriedades analisadas.

Observando os resultados obtidos na Tabela 9, o ganho de resistência à compressão e à tração foi praticamente consolidado nas primeiras idades (14 dias), assim como em Moura, Gonçalves e Leite (2002) e Cruz et al. (2003). Isso vem a confirmar que o resíduo do corte de rochas ornamentais atua como fíler e, portanto, não proporciona grandes ganhos de resistência em idades avançadas por não apresentar atividade química (MEHTA; MONTEIRO, 2008); contudo, as análises foram feitas com os resultados obtidos aos 28 dias.

A Figura 6 apresenta os resultados da análise estatística para o comportamento das misturas no estado endurecido em função da utilização do RCRO para análise da resistência à compressão aos 28 dias de idade.

Figura 5 - Resultados da análise estatística para o ensaio de massa específica para as variáveis resíduo e aditivo

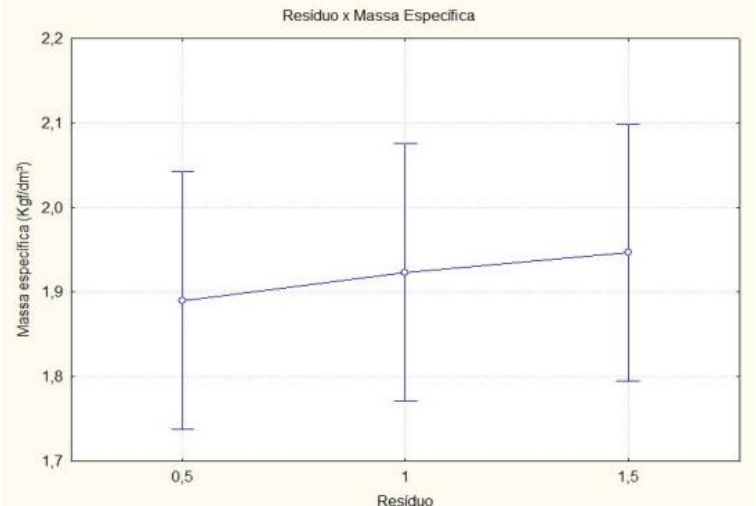

(a)

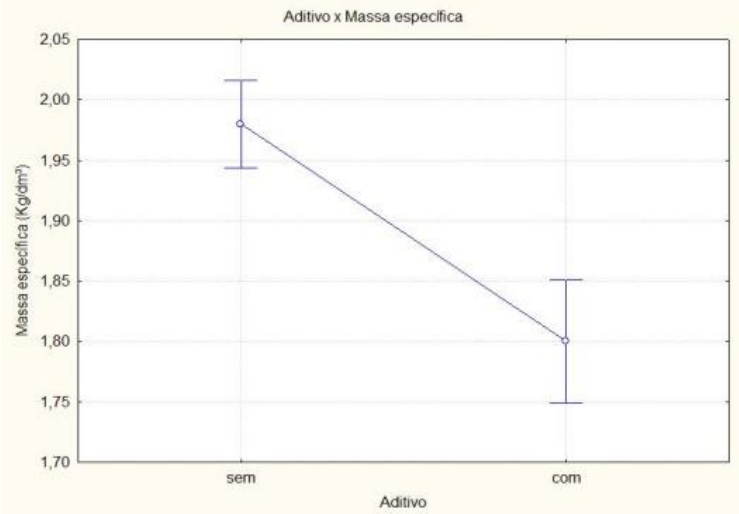

(b)

Tabela 9 - Resultados obtidos nas argamassas no estado endurecido

\begin{tabular}{|c|c|c|c|c|c|}
\hline \multirow[t]{2}{*}{$N^{\circ}$ traço } & \multirow{2}{*}{$\begin{array}{c}\text { Traço em volume } \\
\text { (cimento:cal:resíduo:areia) }\end{array}$} & \multicolumn{2}{|c|}{$\begin{array}{c}\text { Resistência } \\
\text { à compressão }(\mathrm{MPa})\end{array}$} & \multicolumn{2}{|c|}{$\begin{array}{c}\text { Resistência } \\
\text { à tração na flexão (MPa) }\end{array}$} \\
\hline & & 14 dias & 28 dias & 14 dias & 28 dias \\
\hline TR & $1: 0: 0,5: 5$ & 3,26 & 4,10 & 0,89 & 1,35 \\
\hline 2 & $1: 0: 1: 5$ & 3,53 & 4,32 & 1,17 & 1,44 \\
\hline 3 & $1: 0: 1,5: 5$ & 3,68 & 4,50 & 1,50 & 1,75 \\
\hline 4 & $1: 0: 0,5: 5+\mathrm{AD}$ & 2,00 & 2,02 & 0,89 & 0,92 \\
\hline 5 & $1: 0: 1: 5+\mathrm{AD}$ & 3,14 & 3,89 & 1,07 & 1,38 \\
\hline 6 & $1: 0: 1,5: 5+\mathrm{AD}$ & 3,75 & 3,97 & 1,30 & 1,65 \\
\hline 7 & $1: 0,5: 0,5: 5$ & 2,29 & 3,21 & 1,01 & 1,25 \\
\hline 8 & $1: 0,5: 1: 5$ & 2,71 & 3,86 & 1,19 & 1,41 \\
\hline 9 & $1: 0,5: 1,5: 5$ & 3,66 & 4,18 & 1,53 & 1,70 \\
\hline
\end{tabular}

Tabela 10 - Resultados da ANOVA em relação às propriedades no estado endurecido

\begin{tabular}{c|c|c|c}
\hline Variável independente & Variável resposta & $\boldsymbol{P}$ & Significância \\
\hline Resíduo & Resistência à compressão & 0,147244 & Não significativo \\
Cal & Resistência à compressão & 0,88884249 & Não significativo \\
Aditivo & Resistência à compressão & 0,190229 & Não significativo \\
Resíduo & Resistência à tração & 0,00852 & Significativo \\
Cal & Resistência à tração & 0,859084 & Não significativo \\
Aditivo & Resistência à tração & 0,411625 & Não significativo \\
\hline
\end{tabular}

174 Vinco, L. G. F.; Oliveira, J. D. de; Tristão, F. A.; Vieira, G. L. 
Figura 6 - Resultado da análise estatística para o ensaio de resistência à compressão aos 28 dias para a variável resíduo

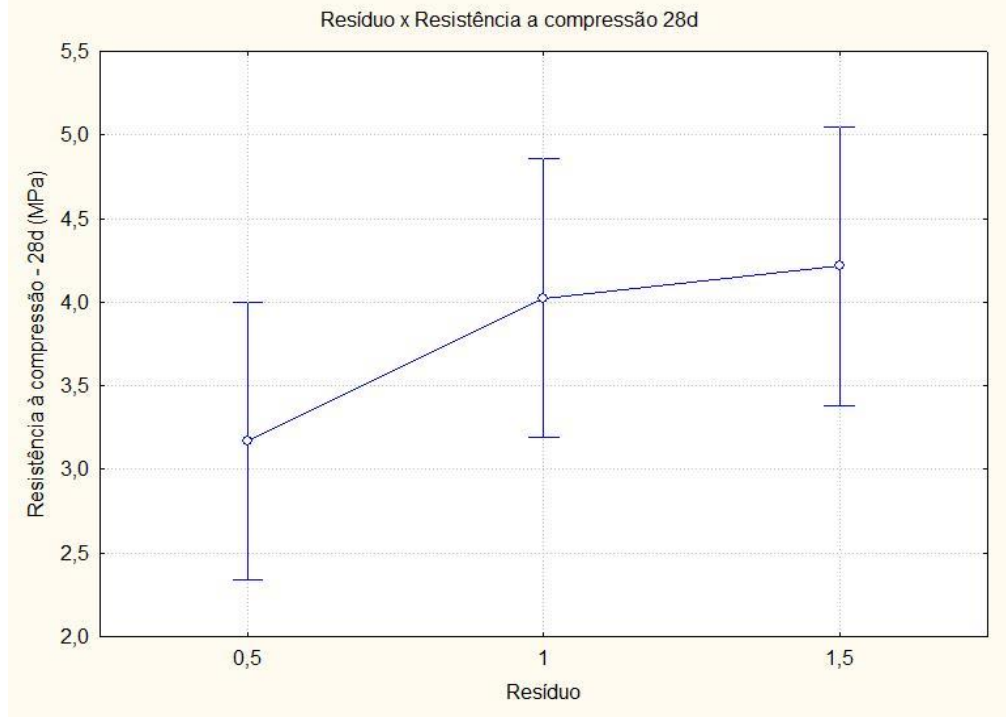

Para a resistência à compressão foi constatada, através da ANOVA, a não significância dos fatores resíduo, cal e aditivo. Apesar disso, a tendência de crescimento da resistência à compressão apresentada na Figura 6 com relação ao RCRO, também observada em Calmon et al. (1997a) e em Tenório, Lameiras e Lima (2005), pode estar ligada ao preenchimento dos vazios da argamassa pelo RCRO, devido a sua elevada finura e, consequentemente, a sua área específica elevada.

A Figura 7 apresenta os resultados da análise estatística para o comportamento das misturas no estado endurecido em função da utilização do RCRO para análise da resistência à tração aos 28 dias de idade.

Com relação à resistência à tração, foi constatada através da ANOVA a significância apenas do fator resíduo, e a não significância dos fatores cal e aditivo. Como observado na Figura 7, o RCRO, devido a sua elevada finura, possivelmente colmatou os poros das argamassas, reduzindo os espaços livres. A combinação desses fatores resultou numa melhor ligação entre os elementos da matriz cimentícia, elevando a resistência à tração, pois, quanto menor a porosidade, maior a resistência à tração das argamassas (ALMEIDA; BRANCO; SANTOS, 2007).

\section{Análise da trabalhabilidade das argamassas em obra}

A trabalhabilidade é uma das principais propriedades das argamassas, porém sua determinação é baseada em julgamentos subjetivos por parte dos operários. Cincotto et al. (1995) citam que a trabalhabilidade corresponde a uma facilidade de manuseio por parte do operário que prepara e aplica a argamassa.

A argamassa com traço 1:0:0,5:5 (cimento:cal:resíduo:areia), em volume, apresentou pouca ou quase nenhuma trabalhabilidade, ou seja, de acordo com os pedreiros ela não apresentava coesão suficiente. Isso refletiu em sua falta de adesão inicial no substrato, tendo havido deslizamento e reflexão do material, o que inviabilizou sua aplicação.

As argamassas 1:0:0,5:5+AD e 1:0,5:0,5:5 (cimento:cal:resíduo:areia), em volume, apresentaram trabalhabilidade aceitável por parte dos pedreiros, mas não boa produtividade, pois ainda não estavam no ponto ideal de plasticidade e, consequentemente, não apresentavam adesão inicial satisfatória. Segundo os pedreiros, era necessário "apertar" (pressionar contra o substrato com a colher de pedreiro a argamassa após seu lançamento) a argamassa toda a vez que esta era lançada. Caso fosse necessário o lançamento de uma segunda camada sobre a primeira, todo o revestimento deslizaria, desprendendo-se da parede, e por esse motivo não foi considerada uma argamassa utilizável em obra. 
Figura 7 - Resultado da análise estatística para o ensaio de resistência à tração aos 28 dias para a variável resíduo

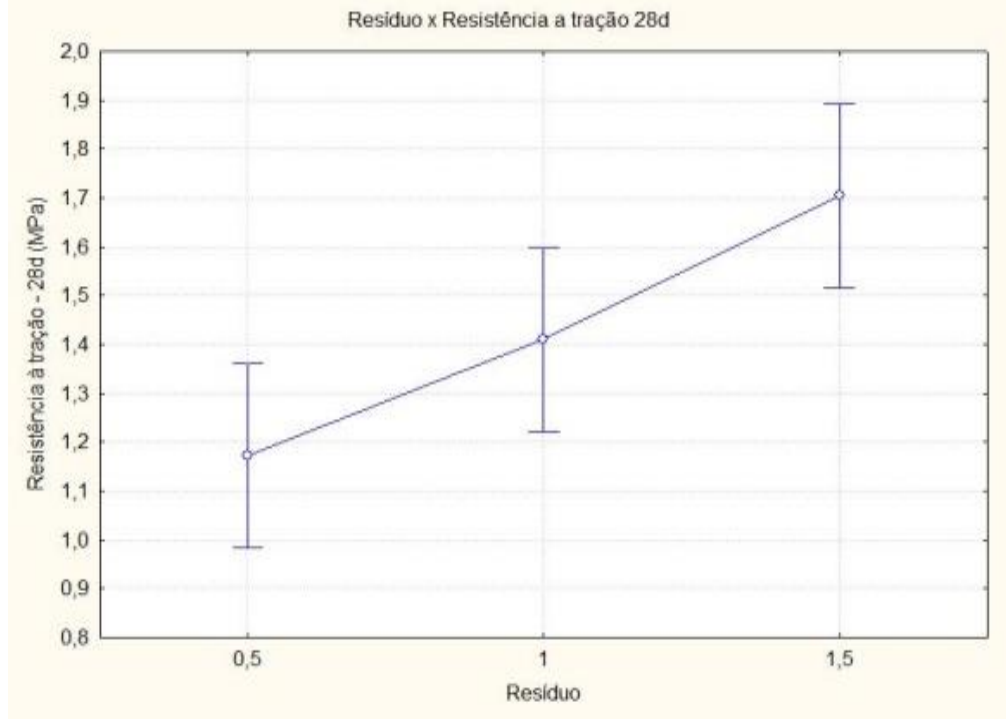

A argamassa com traço 1:0:1:5 (cimento:cal:resíduo:areia), em volume, de acordo com os pedreiros, apresentou boa coesão, porém foi considerada uma argamassa pesada, o que pode ser explicado devido à maior adição de resíduo de corte de rochas ornamentais, que eleva a massa específica da argamassa, como observado nos ensaios realizados em laboratório, apesar de não ter apresentado diferenças significativas nas análises estatísticas. Segundo os pedreiros, é uma argamassa considerada trabalhável, porém, por ser "pesada" (elevada massa específica no estado fresco), não apresenta boa produtividade, pois é necessário maior gasto de energia no lançamento, que ao longo do dia diminui a produtividade dos profissionais.

As argamassas com traços 1:0:1:5+AD e 1:0,5:1:5 (cimento:cal:resíduo:areia), em volume, foram consideradas as melhores argamassas em termos de trabalhabilidade pelos pedreiros que as utilizaram, apresentaram boa coesão, estavam leves, fáceis de espalhar, e aderiram bem no substrato, ou seja, não houve reflexão da argamassa. Segundo os pedreiros, os dois traços são ideais para ser utilizados em obra. De acordo com Carasek (2007), quanto mais leve for a argamassa, mais trabalhável será no longo prazo, por reduz esforço em sua aplicação e resultar em maior produtividade. Também, segundo Calhau (2000), o ar incorporado por meio de um aditivo contribui significativamente para o aumento da trabalhabilidade das argamassas.

As argamassas com adição de $150 \%$ de resíduo em relação ao volume de cimento, com traços
$1: 0: 1,5: 5, \quad 1: 0: 1,5: 5+\mathrm{AD} \quad$ e $\quad 1: 0,5: 1,5: 5$ (cimento:cal:resíduo:areia), em volume, apresentaram, de acordo com os pedreiros, excesso de coesão, o que dificultou o lançamento da argamassa, pois ela tinha forte aderência à colher de pedreiro; consequentemente, houve a necessidade de emprego de maior força durante o lançamento delas. Durante a aplicação da argamassa no substrato todos os pedreiros comentaram a probabilidade de essas argamassas apresentarem fissuras após o processo de cura em função da retração por secagem. A argamassa de traço 1:0,5:1,5:5 (cimento:cal:resíduo:areia), em volume, apresentou fissuras logo após sua aplicação (Figura 8), confirmando o que foi observado pelos pedreiros. Com base nas características descritas, pode-se concluir que essas argamassas não são aplicáveis em obra.

A Tabela 11 resume a classificação dada pelos pedreiros para cada traço, de acordo com os aspectos analisados.

Portanto, analisando os resultados da Tabela 11, é possível concluir que o traço que apresentou melhor desempenho, de acordo com os pedreiros, foi o T5, tendo recebido avaliação "ótima" em todas as propriedades avaliadas. Em seguida, está o T8, que possui três avaliações "ótima" e uma "boa". Por fim, o T2 pode ser considerado o terceiro melhor traço, pois apresenta duas avaliações "regular" e duas "boa". Os demais traços apresentaram desempenho abaixo do esperado, tendo em sua maioria avaliações "regular" ou pelo menos uma avaliação "ruim". 
Figura 8 - Trincas após o lançamento das argamassas com adição de $150 \%$ de resíduo

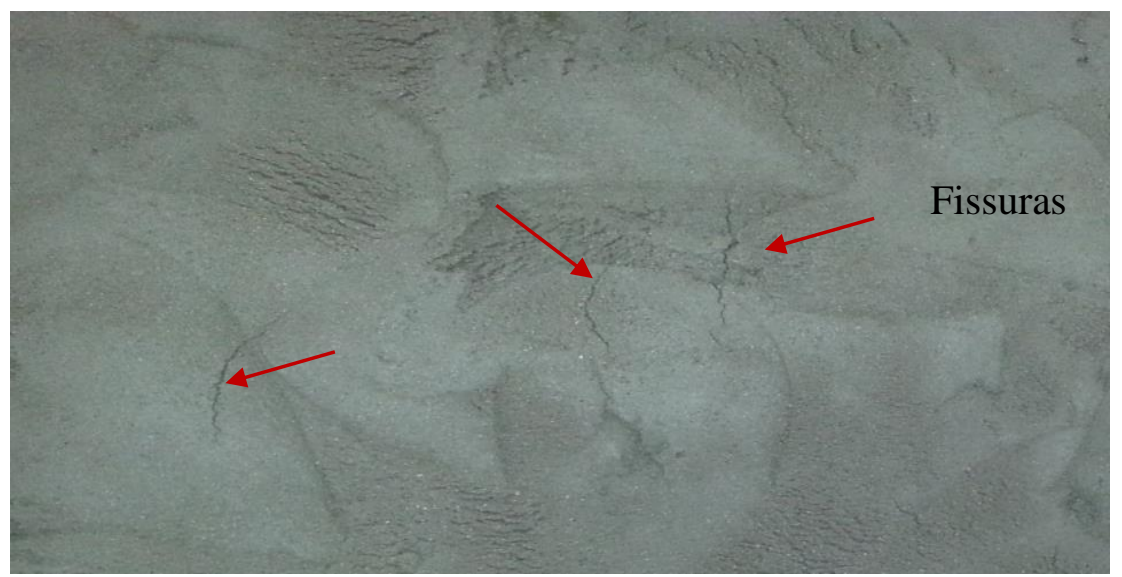

Tabela 11 - Classificação das argamassas em relação à trabalhabilidade de acordo com a avaliação dos pedreiros

\begin{tabular}{c|c|c|c|c|c}
\hline $\begin{array}{c}\mathbf{N}^{\mathbf{o}} \\
\text { Traço }\end{array}$ & $\begin{array}{c}\text { Traço em volume } \\
\text { (cimento:cal:resíduo:areia) }\end{array}$ & Plasticidade & $\begin{array}{c}\text { Adesão } \\
\text { inicial }\end{array}$ & Homogeneidade & Trabalhabilidade \\
\hline TR & $1: 0: 0,5: 5$ & Ruim & Ruim & Boa & Ruim \\
2 & $1: 0: 1: 5$ & Regular & Boa & Boa & Regular \\
3 & $1: 0: 1,5: 5$ & Ruim & Ótima & Boa & Ruim \\
4 & $1: 0: 0,5: 5+\mathrm{AD}$ & Regular & Regular & Boa & Regular \\
5 & $1: 0: 1: 5+\mathrm{AD}$ & Ótima & Ótima & Ótima & Ótima \\
6 & $1: 0: 1,5: 5+\mathrm{AD}$ & Ruim & Ótima & Boa & Ruim \\
7 & $1: 0,5: 0,5: 5$ & Regular & Regular & Boa & Regular \\
8 & $1: 0,5: 1: 5$ & Ótima & Ótima & Boa & Ótima \\
9 & $1: 0,5: 1,5: 5$ & Ruim & Ótima & Boa & Ruim \\
\hline
\end{tabular}

\section{Análise de viabilidade econômica}

De forma a obter os custos para confecção das argamassas utilizadas foram considerados apenas os custos de cada material constituinte das argamassas, não envolvendo custos de mão de obra nem custos indiretos, como, por exemplo, locação de equipamentos, energia, etc. Para tanto, realizouse uma pesquisa em empresas que comercializam os materiais necessários.

Os valores expostos na Tabela 12 correspondem a uma média do preço praticado por três fornecedores diferentes. Com relação à areia lavada, os valores são correspondentes apenas às empresas extratoras desse material, sendo considerado o transporte até a Grande Vitória.

Com relação ao RCRO, adotou-se que não haveria custo para a obtenção desse material, uma vez que ele é rejeito da indústria. Seu custo para as empresas produtoras de rochas ornamentais é reduzido porque não se faria necessário transportálo e depositá-lo em aterros apropriados; seria apenas repassado às construtoras que demonstrassem interesse no material.
Entretanto, o custo do transporte até as construtoras não foi considerado para efeito de composição de custo, pois, segundo a Instrução Normativa n ${ }^{\circ}$ 019/2005 do Iema do Espírito Santo, "compete aos estabelecimentos de beneficiamento de rochas ornamentais a responsabilidade e os custos relativos ao sistema de gerenciamento de resíduos sólidos e efluentes líquidos desde sua geração até sua destinação final" (ESPÍRITO SANTO, 2005).

Por fim, não há custo de processamento do resíduo para ser utilizado como insumo na produção de argamassa, como secagem e destorroamento, uma vez que neste trabalho o resíduo foi utilizado in natura.

Na Tabela 13 encontram-se os valores de consumo de cada material para a produção de $1 \mathrm{~m}^{3}$ de cada argamassa analisada e também para a produção de uma argamassa tradicional, que é comumente utilizada em obra com traço 1:1:6 (cimento:cal:areia), em volume.

A composição de custo unitário de cada argamassa é mostrada na Tabela 14. 
Tabela 12 - Preço médio de cada insumo da argamassa na Grande Vitória em julho de 2014

\begin{tabular}{c|c|c}
\hline Produto & Qte. & $\mathbf{R} \$$ \\
\hline Cimento $(\mathrm{kg})$ & 50,00 & 20,00 \\
Aditivo $(\mathrm{l})$ & 1,00 & 10,00 \\
Areia $\left(\mathrm{m}^{3}\right)$ & 1,00 & 50,00 \\
Água $\left(\mathrm{m}^{3}\right)$ & 1,00 & 3,50 \\
Cal $(\mathrm{kg})$ & 20,00 & 10,00 \\
\hline
\end{tabular}

Tabela 13 - Consumo de materiais para cada traço avaliado

\begin{tabular}{c|c|c|c|c|c|c|c}
\hline $\begin{array}{c}\mathbf{N}^{\mathbf{o}} \\
\text { Traço }\end{array}$ & $\begin{array}{c}\text { Traço em volume } \\
\text { (cimento:cal:resíduo:areia) }\end{array}$ & $\begin{array}{c}\text { Cimento } \\
\left(\mathbf{k g} / \mathbf{m}^{\mathbf{3}}\right)\end{array}$ & $\begin{array}{c}\mathbf{R C R O} \\
\left(\mathbf{k g} / \mathbf{m}^{\mathbf{3}}\right)\end{array}$ & $\begin{array}{c}\text { Cal } \\
\left(\mathbf{k g} / \mathbf{m}^{\mathbf{3}}\right)\end{array}$ & $\begin{array}{c}\text { Areia } \\
\left(\mathbf{k g} / \mathbf{m}^{\mathbf{3}}\right)\end{array}$ & $\begin{array}{c}\text { Água } \\
\left(\mathbf{l} / \mathbf{m}^{\mathbf{3}}\right)\end{array}$ & $\begin{array}{c}\text { Aditivo } \\
\left(\mathbf{l} / \mathbf{m}^{\mathbf{3}}\right)\end{array}$ \\
\hline TR & $1: 0: 0,5: 5$ & 201 & 137 & - & 1.172 & 250 & - \\
2 & $1: 0: 1: 5$ & 187 & 256 & - & 1.100 & 258 & - \\
3 & $1: 0: 1,5: 5$ & 176 & 360 & - & 1.031 & 269 & - \\
4 & $1: 0: 0,5: 5+\mathrm{AD}$ & 201 & 137 & - & 1.172 & 226 & 0,402 \\
5 & $1: 0: 1: 5+\mathrm{AD}$ & 187 & 256 & - & 1.100 & 231 & 0,374 \\
6 & $1: 0: 1,5: 5+\mathrm{AD}$ & 176 & 360 & - & 1.031 & 237 & 0,352 \\
7 & $1: 0,5: 0,5: 5$ & 195 & 133 & 62 & 1.141 & 238 & - \\
8 & $1: 0,5: 1: 5$ & 182 & 248 & 58 & 1.066 & 249 & - \\
9 & $1: 0,5: 1,5: 5$ & 170 & 360 & 54 & 1.000 & 265 & - \\
10 & $1: 1: 0: 6$ & 180 & 0 & 115 & 1.264 & 270 & - \\
\hline
\end{tabular}

Tabela 14 - Custo para produzir $1 \mathrm{~m}^{3}$ de argamassa

\begin{tabular}{|c|c|c|c|c|c|c|c|c|}
\hline $\begin{array}{c}\mathbf{N}^{\mathbf{0}} \\
\text { Traço }\end{array}$ & $\begin{array}{c}\text { Traço em volume } \\
\text { (cimento:cal:resíduo:areia) }\end{array}$ & $\begin{array}{c}\text { Cimento } \\
(\mathbf{R} \$)\end{array}$ & $\begin{array}{c}\text { RCRO } \\
(\mathbf{R} \$)\end{array}$ & $\begin{array}{r}\text { Cal } \\
(\mathbf{R} \$)\end{array}$ & $\begin{array}{c}\text { Areia } \\
(\mathbf{R} \$)\end{array}$ & $\begin{array}{c}\text { Água } \\
(\mathbf{R} \$)\end{array}$ & $\begin{array}{c}\text { Aditivo } \\
\text { (R\$) }\end{array}$ & $\begin{array}{l}\text { Total } \\
(\mathbf{R} \$)\end{array}$ \\
\hline TR & $1: 0: 0,5: 5$ & 80,40 & 0 & 0 & 45,43 & 0,87 & 0 & 126,70 \\
\hline 2 & $1: 0: 1: 5$ & 74,80 & 0 & 0 & 42,64 & 0,90 & 0 & 118,34 \\
\hline 3 & $1: 0: 1,5: 5$ & 70,40 & 0 & 0 & 39,96 & 0,94 & 0 & 111,30 \\
\hline 4 & $1: 0: 0,5: 5+\mathrm{AD}$ & 80,40 & 0 & 0 & 45,43 & 0,79 & 4,02 & 130,64 \\
\hline 5 & $1: 0: 1: 5+\mathrm{AD}$ & 74,80 & 0 & 0 & 42,64 & 0,81 & 3,74 & 121,98 \\
\hline 6 & $1: 0: 1,5: 5+\mathrm{AD}$ & 70,40 & 0 & 0 & 39,96 & 0,83 & 3,52 & 114,71 \\
\hline 7 & $1: 0,5: 0,5: 5$ & 78,00 & 0 & 31,00 & 44,22 & 0,83 & 0 & 154,06 \\
\hline 8 & $1: 0,5: 1: 5$ & 72,80 & 0 & 29,00 & 41,32 & 0,87 & 0 & 143,99 \\
\hline 9 & $1: 0,5: 1,5: 5$ & 68,00 & 0 & 27,00 & 38,76 & 0,93 & 0 & 134,69 \\
\hline 10 & $1: 1: 0: 6$ & 72,00 & 0 & 57,50 & 48,99 & 0,95 & 0 & 179,44 \\
\hline
\end{tabular}

Observa-se pela Tabela 14 que todos os traços analisados neste trabalho possuem custo de produção inferior ao da argamassa com traço 1:1:6 (cimento:cal:areia), em volume. Isso pode ser explicado pelo consumo elevado de cal no traço comumente utilizado em obra, pois o consumo dos outros materiais constituintes da argamassa varia pouco quando comparado com os outros traços estudados. Outro fator importante é que com o aumento da adição do RCRO têm-se a diminuição do consumo de cimento e a consequente queda no custo por metro cúbico das argamassas. Ainda deve ser considerado que no processo de beneficiamento de rochas ornamentais com teares convencionais o RCRO possui em sua composição a cal, que pode favorecer o desempenho técnico e econômico das argamassas de revestimento com adição desse material.
Na Tabela 15 são apresentados os resultados obtidos para todas as propriedades avaliadas em laboratório e em obra, e o custo de produção por metro cúbico. Assim, observando os resultados dos ensaios realizados em laboratório juntamente com os resultados obtidos em obra e o custo, conclui-se que os traços que apresentam a melhor relação custo-benefício são os traços 1:0:1:5+AD e 1:0,5:1:5 (cimento:cal:resíduo:areia), em volume. Esses traços apresentam redução no custo de produção de $1 \mathrm{~m}^{3}$ de argamassa de aproximadamente $32 \%$ e $20 \%$ respectivamente.

Com base na Tabela 15 é possível fazer uma estimativa de custo para comparar em termos financeiros as diferenças entre os traços 1:0:1:5+AD $\quad$ e $1: 0,5: 1: 5$ (cimento:cal:resíduo:areia), em volume, que apresentaram a melhor relação custo-benefício

178 Vinco, L. G. F.; Oliveira, J. D. de; Tristão, F. A.; Vieira, G. L. 
com uma argamassa comumente utilizada nos canteiros (1:1:0:6). Por exemplo, para um edifício de médio porte com aproximadamente $3.000 \mathrm{~m}^{2} \mathrm{de}$ obra e um consumo baseado em $0,5 \mathrm{~m}^{3}$ de argamassa por metro quadrado de obra, como observado em Paliari, Souza e Andrade (2008), pode-se chegar a valores gastos como os observados na Tabela 16.

Dessa forma, pode-se afirmar que, além dos benefícios ambientais trazidos pela utilização do resíduo do corte de rochas ornamentais em argamassas, tem-se também redução substancial no custo de produção dela, o que contribui para a diminuição dos custos totais da obra.

\section{Conclusões}

A partir da análise dos resultados encontrados nos ensaios realizados no estado fresco, notou-se melhora nas propriedades de retenção de água e de consistência, pois o RCRO possui finura equivalente à do cimento e, portanto, contribui para a colmatação dos poros da argamassa. Também se levantou o fato de o RCRO possuir em sua composição a cal, derivada do processo de beneficiamento, que possui avidez por água e pode contribuir para o aumento da retenção de água e de consistência.
Apesar de os resultados das análises estatísticas terem comprovado que não havia influência significativa na resistência à compressão, os resultados obtidos nos ensaios realizados mostram uma tênue tendência de crescimento nas resistências à compressão e tração. Esse comportamento se deve, possivelmente, à colmatação dos poros pelo RCRO e também à alta retenção de água dos traços.

$\mathrm{O}$ processo de mistura proposto se mostrou eficiente para eliminar as etapas de secagem e destorroamento para o uso do RCRO, que se mostrou tecnicamente viável em sua utilização no estado in natura. No estado fresco a argamassa se mostrou homogênea e não apresentou aglomerados de resíduo. Porém, no estado endurecido esses aglomerados se evidenciaram em pequenos pontos isolados, que, de acordo com os resultados, não afetam potencialmente o uso da argamassa.

Os dois traços que apresentaram o melhor desempenho em obra foram os traços 1:0:1:5+AD e 1:0,5:1:5 em volume (cimento:cal:resíduo:areia), por terem, de acordo com os pedreiros, boa plasticidade, adesão inicial, homogeneidade e trabalhabilidade.

Tabela 15 - Resumo dos resultados

\begin{tabular}{c|c|c|c|c|c|c|c}
\hline $\mathbf{( 1 )}$ & $\mathbf{( 2 )}$ & $\mathbf{( 3 )}$ & $\mathbf{( 4 )}$ & $\mathbf{( 5 )}$ & $\mathbf{( 6 )}$ & $\mathbf{( 7 )}$ & $\mathbf{( 8 )}$ \\
\hline $1: 0: 0,5: 5$ & 86 & 55 & 1,99 & 4,10 & 1,35 & Ruim & 126,70 \\
$1: 0: 1: 5$ & 89 & 62 & 2,00 & 4,32 & 1,44 & Regular & 118,34 \\
$1: 0: 1,5: 5$ & 92 & 70 & 2,02 & 4,50 & 1,75 & Ruim & 111,30 \\
$1: 0: 0,5: 5+\mathrm{AD}$ & 90 & 68 & 1,78 & 2,02 & 0,92 & Regular & 130,64 \\
$1: 0: 1: 5+\mathrm{AD}$ & 92 & 72 & 1,80 & 3,89 & 1,38 & Ótima & 121,98 \\
$1: 0: 1,5: 5+\mathrm{AD}$ & 95 & 76 & 1,82 & 3,97 & 1,65 & Ruim & 114,71 \\
$1: 0,5: 0,5: 5$ & 93 & 75 & 1,90 & 3,21 & 1,25 & Regular & 154,06 \\
$1: 0,5: 1: 5$ & 95 & 76 & 1,97 & 3,86 & 1,41 & Ótima & 143,99 \\
$1: 0,5: 1,5: 5$ & 97 & 79 & 2,00 & 4,18 & 1,70 & Ruim & 134,69 \\
\hline
\end{tabular}

Nota: Legenda:
(1) Traço em volume (cimento:cal:resíduo:areia);
(2) retenção de água (\%);
(3) retenção de consistência (\%);
(4) massa específica $\left(\mathrm{kg} / \mathrm{dm}^{3}\right)$;
(5) resistência à compressão $(\mathrm{MPa})$;
(6) resistência à tração $(\mathrm{MPa})$;
(7) trabalhabilidade; e
(8) custo $\left(R \$ / m^{3}\right)$.

Tabela 16 - Custo total de produção de argamassa para uma obra de médio porte $\left(3.000 \mathrm{~m}^{2}\right)$

\begin{tabular}{c|c|c}
\hline $\begin{array}{c}\text { Traço em volume } \\
\text { (cimento:cal:resíduo:areia) }\end{array}$ & $\begin{array}{c}\text { Custo } \\
\left(\mathbf{R} \$ \mathbf{m}^{3}\right)\end{array}$ & $\begin{array}{c}\text { Total } \\
(\mathbf{R} \$ \mathbf{)}\end{array}$ \\
\hline $1: 0: 1: 5+\mathrm{AD}$ & 121,98 & 182973 \\
$1: 0,5: 1: 5$ & 143,99 & 215985 \\
$1: 1: 0: 6$ & 179,44 & 269155 \\
\hline
\end{tabular}


Com relação ao custo de produção das argamassas, com a adição do RCRO o consumo de cimento é reduzido, o que gera menor custo de produção da argamassa, e, portanto, os traços que contêm resíduo se tornam mais viáveis economicamente do que um traço que é comumente utilizado em obra; por exemplo, o traço 1:1:6 (cimento:cal:areia), em volume.

Somando os resultados encontrados em laboratório com a análise qualitativa realizada em obra e o custo de produção das argamassas estudadas, conclui-se que os traços que apresentam os melhores custos-benefícios são 1:0:1:5+AD e 1:0,5:1:5 (cimento:cal:resíduo:areia), em volume.

Por fim, a partir dos resultados encontrados nos ensaios realizados tanto no estado fresco quanto no endurecido das argamassas, aliados à análise feita em obra e à análise de custo para produção de cada traço estudado, pode-se dizer que a incorporação do RCRO em argamassas de revestimento é tecnicamente viável e que $100 \%$ de incorporação do resíduo é o teor ideal encontrado neste trabalho.

\section{Referências}

AL-AKHRAS, N. M.; ABABNEH, A.; ALARAJI, W. A. Using Burnt Stone Slurry in Mortar Mixes. Construction and Building Materials, v. 24, p. 2658-2663, 2010.

ALMEIDA, N.; BRANCO, F.; SANTOS, J. R. Recycling of Stone Slurry in Industrial Activities: application to concrete mixtures. Building and Environment, v. 42, n. 2, p. 810-819, 2007.

ARAÚJO, E. S.; GOMES V. A.; FERREIRA, H. C. Caracterização dos Resíduos da Serragem de Granitos a Produção de Tijolos Sílica-Cal Para Uso em Construção Civil. In: CONGRESSO BRASILEIRO DE CERÂMICA, 46., São Paulo, 2002. Anais... São Paulo: Abceram, 2002.

ASSOCIAÇÃO BRASILEIRA DA INDÚSTRIA DE ROCHAS ORNAMENTAIS. Exportações Estaduais de Rochas Ornamentais e de Revestimento em 2012. Informe 02/2013. São Paulo, 2013. Disponível em:

<http://www.abirochas.com.br>. Acesso em: 1 abr. 2013.

\section{ASSOCIAÇÃO BRASILEIRA DE NORMAS} TÉCNICAS. NBR 11579: cimento Portland: determinação do índice de finura por meio da peneira $75 \mu \mathrm{m}$ ( $\mathrm{n}^{\circ}$ 200). Rio de Janeiro, 2012.

ASSOCIAÇÃO BRASILEIRA DE NORMAS TÉCNICAS. NBR 12127: gesso para a construção: determinação das propriedades físicas do pó: método de ensaio. Rio de Janeiro, 1991.
ASSOCIAÇÃO BRASILEIRA DE NORMAS TÉCNICAS. NBR 13276: argamassa para assentamento e revestimento de paredes e tetos: preparo da mistura e determinação do índice de consistência. Rio de Janeiro, 2005a.

\section{ASSOCIAÇÃO BRASILEIRA DE NORMAS} TÉCNICAS. NBR 13277: argamassa para assentamento e revestimento de paredes e tetos: determinação da retenção de água. Rio de Janeiro, $2005 \mathrm{c}$.

\section{ASSOCIAÇÃO BRASILEIRA DE NORMAS}

TÉCNICAS. NBR 13278: argamassa para assentamento e revestimento de paredes e tetos: determinação da densidade de massa e do teor de ar incorporado. Rio de Janeiro, 2005b.

\section{ASSOCIAÇÃO BRASILEIRA DE NORMAS TÉCNICAS. NBR 13279: argamassa para} assentamento e revestimento de paredes e tetos: determinação da resistência à tração na flexão e a compressão axial. Rio de Janeiro, 2005d.

\section{ASSOCIAÇÃO BRASILEIRA DE NORMAS} TÉCNICAS. NBR 16372: cimento Portland e outros materiais em pó: determinação da finura pelo método de permeabilidade ao ar (método de Blaine). Rio de Janeiro, 2015.

\section{ASSOCIAÇÃO BRASILEIRA DE NORMAS} TÉCNICAS. NBR 7215: cimento Portland: determinação da resistência à compressão. Rio de Janeiro, 1996a.

\section{ASSOCIAÇÃO BRASILEIRA DE NORMAS TÉCNICAS. NBR 9290: cal hidratada para argamassas: determinação de retenção de água: método de ensaio. Rio de Janeiro, 1996b.}

\section{ASSOCIAÇÃO BRASILEIRA DE NORMAS TÉCNICAS. NBR NM 23: cimento Portland e outros materiais: determinação da massa específica. Rio de Janeiro, 2001.}

\section{ASSOCIAÇÃO BRASILEIRA DE NORMAS TÉCNICAŞ. NBR NM 248: agregados: determinação da composição granulométrica. Rio de Janeiro, 2003b.}

ASSOCIAÇÃO BRASILEIRA DE NORMAS TÉCNICAS. NBR NM 43: cimento Portland: determinação da pasta de consistência normal. Rio de Janeiro, 2003b.

\section{ASSOCIAÇÃO BRASILEIRA DE NORMAS TÉCNICAS. NBR NM 45: agregados: determinação da massa unitária e do volume de vazios, 2006.}

ASSOCIAÇÃO BRASILEIRA DE NORMAS
TÉCNICAS. NBR NM 52: agregado miúdo:
determinação da massa específica e da massa
específica aparente. Rio de Janeiro, 2009.


ASSOCIAÇÃO BRASILEIRA DE NORMAS TÉCNICAS. NBR NM 65: cimento Portland: determinação do tempo de pega. Rio de Janeiro, 2003a.

\section{ASSOCIAÇÃO BRASILEIRA DE NORMAS} TÉCNICAS. NBR NM 76: cimento Portland: determinação da finura pelo método de permeabilidade ao ar (Método de Blaine). Rio de Janeiro, 1998.

BARROS, A. R. et al. Estudos e Resultados Sobre a Utilização do Resíduo do Corte do Mármore e Granito em Materiais à Base de Cimento. In: ENCONTRO NACIONAL DO AMBIENTE CONSTRUÍDO, 11., Florianópolis, 2006. Anais... Florianópolis: ANTAC, 2006.

CALHAU, E. L. Argamassa de Revestimento Com Aditivo Incorporador de Ar: propriedades e recomendações. Vitória, 2000. Dissertação (Mestrado em Engenharia Civil) - Escola de Engenharia, Universidade Federal do Espírito Santo, Vitória, 2000.

CALMON, J. L. et al. Aproveitamento do Resíduo de Corte de Granito Para a Produção de Argamassas de Assentamento. In: SIMPÓSIO BRASILEIRO DE TECNOLOGIA DAS ARGAMASSAS, 2., Salvador, 1997. Anais... Salvador: ANTAC, 1997a.

CALMON, J. L. et al. Reciclagem do Resíduo de Corte de Granito Para a Produção de Argamassas. In: ENCONTRO NACIONAL SOBRE EDIFICAÇÕES E COMUNIDADES SUSTENTÁVEIS, 1., Canela, 1997. Anais... Canela: ANTAC, 1997b.

CARASEK, H. Materiais de Construção Civil e Princípios de Ciência e Engenharia de Materiais. São Paulo: Ibracon, 2007.

CINCOTTO, M. A. et al. Argamassas de Revestimento: características, propriedades e métodos de ensaio. Boletim 68 IPT, São Paulo, p. 118, 1995.

COLANGELO, F.; MARROCCOLI, M.; CIOFFI, R. Properties of Self-Levelling Concrete Made With Industrial Wastes. RILEM Proceedings Pro, v. 40, p. 580-589, 2010.

CORINALDESI, V.; MORICONI, G.; NAIK, T. R. Characterization of Marble Powder for Its Use in Mortar and Concrete. Construction and Building Materials, v. 24, p. 113-117, 2010.
CRUZ, D. F. M. et al. Estudo das Propriedades Mecânicas de Argamassas Produzidas Utilizandose Resíduo do Corte de Mármore e Granito. In: SEMINÁRIO DESENVOLVIMENTO SUSTENTÁVEL E A RECICLAGEM NA CONSTRUÇÃO CIVIL, 6., São Paulo, 2003. Anais... São Paulo: Ibracon, 2003.

CENTRO DE TECNOLOGIA DO GÁS E ENERGIAS RENOVÁVEIS. Relatóro de Análise de Materiais: análise química semiquantitativa por fluorescência de raios-X (FRX) com Perda ao Fogo (PF). Laboratório do Centro de Tecnologias do Gás e Energias Renováveis-LTG-ER:

Laboratório de Ensaios de Materiais, Rio Grande do Norte. 2016.

ESPÍRITO SANTO. Instituto Estadual do Meio Ambiente e Recursos Hídricos. Secretaria Estadual do Meio Ambiente e Recursos Hídricos. Instrução Normativa n 019, de 17 de agosto de 2005. Dispõe sobre a definição dos procedimentos de licenciamento das atividades de beneficiamento de rochas ornamentais. Disponível em <http://www.meioambiente.es.gov.br/default.asp?p agina $=18190>$. Acesso em: 18 mar. 2013.

GONÇALVES, J.; MOURA, W.; DAL MOLIN, D. Avaliação da Influência da Adição do Resíduo de Corte de Granito (RCG), Como Adição, em Propriedades Mecânicas do Concreto. Ambiente Construído, Porto Alegre, v. 2, n. 1, p. 53-68, jan./mar. 2002.

JOHN, V. M. Pesquisa e Desenvolvimento de Mercado Para Resíduos. In: WORKSHOP RECICLAGEM E REUTILIZAÇÃO DE RESÍDUOS COMO MATERIAIS DE CONSTRUÇÃO CIVIL, São Paulo, 1996. Anais... São Paulo: Epusp; ANTAC, 1996.

MEHTA, P. K.; MONTEIRO, P. J. M. Concreto: microestrutural, propriedades e materiais. 3. ed. São Paulo: Ibracon, 2008.

MOURA, W. A. et al. Utilização de Resíduo de Serragem de Rochas Ornamentais (RSRO) Como Substituição Parcial do Cimento na Produção de Blocos Pré-Moldados de Argamassa. In: ENCONTRO NACIONAL DE TECNOLOGIA NO AMBIENTE CONSTRUÍDO, 11., Florianópolis, 2006. Anais... Florianópolis, 2006. MOURA, W. A.; GONÇALVES, J. P.; LEITE, R. S. Utilização do Resíduo de Corte de Mármore e Granito em Argamassas de Revestimento e Confecção de Lajotas Para piso. Sitientibus, v. 26, p. 49-61, 2002. 
PALIARI, J. C; SOUZA, E. L.; ANDRADE, A. C. Estudo do Consumo de Argamassas de Revestimentos Interno e Externo nos Canteiros de Obras. São Paulo, 2008. Disponível em: <http://www.globalconstroi.com>. Acesso em: 1 abr. 2013.

SOARES, R. B. Contribuição ao Estudo da Durabilidade de Concretos Produzidos Com a Incorporação de Resíduo do Beneficiamento de Rochas Ornamentais. Vitória, 2014. Dissertação (Mestrado em Engenharia Civil) - Programa de Pós-Graduação em Engenharia Civil, Universidade Federal do Espírito Santo, Vitória, 2014.

TENÓRIO, J. J. L.; LAMEIRAS, R. de M.; LIMA, L. A. de. Desempenho de Argamassas Produzidas Com Resíduo do Beneficiamento de Chapas de Granito (RBCG). In: SIMPÓSIO BRASILEIRO DE TECNOLOGIA DE ARGAMASSA, 6.; INTERNATIONAL SYMPOSIUM ON MORTARS TECHNOLOGY, 1., Florianópolis, 2005. Anais... Florianópolis, 2005.
ULIANA, J. G. Estudo de Tratamento Térmico Para Aplicação da Lama do Beneficiamento de Rochas Ornamentais Como Substituição Parcial de Cimento. Vitória, 2013. Dissertação (Mestrado em Engenharia Civil) - Escola de Engenharia Civil, Universidade Federal do Espírito Santo, Vitória, 2014.

VARDHAN, K. et al. Mechanical Properties and Microstructural Analysis of Cement Mortar Incorporating Marble Powder as Partial Replacement of Cement. Construction and Building Materials, v. 96, p. 615-621, 2015.

VIAPOL. Ficha Técnica do Aditivo Viacal. São Paulo, 2014.

\section{Agradecimentos}

Os autores agradecem ao Laboratório de Ensaios em Materiais de Construção (Lemac) e ao Laboratório de Difração de Raios X do CCE da Universidade Federal do Espírito Santo.

\footnotetext{
Luís Gustavo Fiorese Vinco

Departamento de Engenharia Civil, Centro Tecnológico | Universidade Federal do Espírito Santo | Av. Fernando Ferrari, 514, Goiabeiras | Vitória - ES - Brasil | CEP 29075-510 | Tel.: (27) 998926267 | E-mail: gustavo.fiorese@gmail.com

Julia Delboni de Oliveira

Departamento de Engenharia Civil, Centro Tecnológico | Universidade Federal do Espírito Santo | Tel.: (27) 99909-3889 |

E-mail: juliadelboni@gmail.com
}

Fernando Avancini Tristão

Centro Tecnológico | Universidade Federal do Espírito Santo | Av. Fernando Ferrari, s/n, Goiabeiras, Campus Universitário | Vitória - ES - Brasil | CEP 29060-900 | Tel.: (27) 3335-2694 | E-mail: fernando.avancini@ct.ufes.br

Geilma Lima Vieira

Departamento de Engenharia Civil, Centro Tecnológico | Universidade Federal do Espírito Santo | Tel.: (27) 4009-2706 |

E-mail: geilma.vieira@gmail.com

Revista Ambiente Construído

Associação Nacional de Tecnologia do Ambiente Construído

Av. Osvaldo Aranha, $99-3^{\circ}$ andar, Centro

Porto Alegre - RS - Brasil

CEP $90035-190$

Telefone: +55 (51) 3308-4084

Fax: +55 (51) 3308-4054

www.seer.ufrgs.br/ambienteconstruido

E-mail: ambienteconstruido@ufrgs.br

182 Vinco, L. G. F.; Oliveira, J. D. de; Tristão, F. A.; Vieira, G. L. 